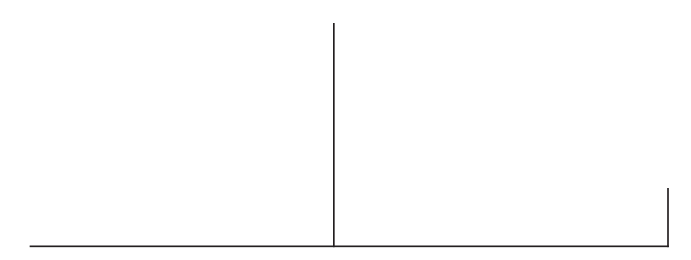

\title{
Em torno da causalidade e da causalidade psíquica*
}

\author{
Olivier Douville
}

O projeto deste artigo é retraçar um percurso. Partir do "mútuo engendramento do aparelho psíquico e do aparelho de linguagem" (A. Green) para encontrar, no exame dos modelos do pensamento e do julgamento em Freud, os próprios princípios daquilo que, ao causar o psíquico, causa o sujeito e suas linhas de divisão. Em seguida, examinar a problemática da realidade da fala e do objeto no tratamento, para também contribuir com alguns grãos no debate: psicanálise e epistemologia contemporânea.

Mostrando, aqui, que a causalidade de que se trata na intimidade do sujeito não é um "ponto de partida" dado para uma programação irredutível do sentido vivido, tentaremos indicar que a racionalidade psicanalítica vai bem mais longe do que queremos admitir.

* Tradução de Monica Seincman. 


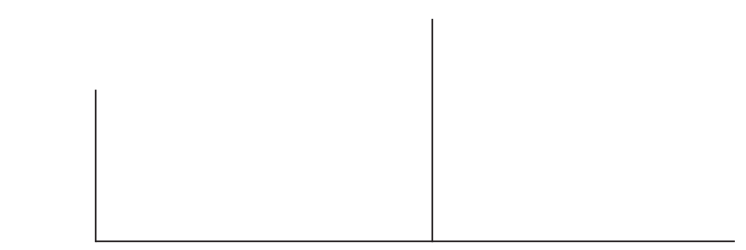

A coisa analítica não será matemática. É justamente por isso que o discurso do analista se diferencia do discurso científico.

J. Lacan (Seminário XI)

A experiência analítica testemunha a dificuldade de reconhecer, no sujeito, uma esfera autônoma, própria a ele, de seu pensamento. A hipótese do inconsciente se fundou a partir de uma constatação: a de uma dimensão que perturba a ilusão de uma transparência do pensamento em si mesma.

Munir-se desta hipótese significa operar uma reviravolta radical de perspectiva, já que o processo de simbolização do conhecimento é, por nós, interrogado em uma zona em que é possível haver representação, mas sem nenhum sujeito que a possa pensar. E isto é um paradoxo, considerar a existência de uma zona em que se depositaria pensamento, lugar em que "isso pensa", mas no seio da qual se desenrola pensamento sem sujeito. O exame dos modelos do pensamento em Freud nos ensina que uma clínica psicanalítica do pensamento não encontra seu campo senão ao se fundar sobre o estudo das formações do inconsciente, reagrupadas e organizadas em torno de uma possibilidade de construção do fantasma, dando as chaves singulares de posição subjetiva.

A psicanálise como teoria em nada é separável da psicanálise como método e da psicanálise como tratamento. A própria idéia que temos da sessão analítica, do tratamento-tipo - porque esta situação está entrelaçada com a regra fundamental - deve-se à exclusão da pretensão que teríamos de relacionar demasiadamente a idéia de verdade com a dos frutos que um pensamento sempre concentrado colheria, ligado a vetores de orientação expressamente determinados.

A psicanálise freudiana ocupa um lugar privilegiado em nosso saber. Isto se deve ao modo particularmente perigoso com que ela destruiu nossos princípios de episteme através de seu próprio uso da definição do inconsciente. Há aí uma razão que tem a ver com o objeto que oferece 
para si, mas que está mais relacionada com o caminho pelo qual ela se dirige para o ponto externo ao discurso que o organiza.

A prática analítica encontra sempre um ponto que qualifica o exercício de impossível. Freud verá nisto, escrevendo "Construções em análise" e "Análise terminável e interminável" , a passagem determinante do desenlace de um tratamento, indicando que a possibilidade de um fim de análise reside na assunção do momento de báscula da posição subjetiva em que se inventa uma conversão da singularidade objetiva nas lógicas da sexuação.

A interrogação freudiana relativa às condições do pensamento abre-se sobre um campo de pesquisas cujo objeto é a construção que divide a realidade psíquica. Poder-se-ia colocar de outra forma: não há construção do sujeito que não o divida em um duplo movimento, tanto em relação ao que ele não é e ao que nenhuma imagem lhe permitirá que se reúna (a alteridade simbólica), quanto em relação ao que ele perdeu em virtude da humanização de seu corpo (isto é, o objeto conservado na vida fantasmática inconsciente). Esta proposição expressa, portanto, uma divisão: entre o registro do ser e o do pensar, é necessário propor um elemento inicial ao sujeito que é aquele do fantasma, que trabalha em surdina.

O aparelho psíquico certamente é um modelo. Sabe-se também que ele é um sítio em tensão. Essa tensão é feita pelos usos das escrituras de revolvimento e transposição. A concepção do aparelho psíquico o designa de modo totalmente dinâmico como um operador de passagem entre tratamento, método e metapsicologia. Ao definir o inconsciente por pensamentos e não por forças obscuras e vitais ou por imagens arquetípicas, a psicanálise freudiana extrai a questão do sujeito de uma tripla cenografia:

1. O título original do artigo de Freud é "Die eindliche und die eindliche analyse" (sic). Assinalamos, na bibliografia, sob o título de sua tradução francesa mais recente e mais "oficial": "A análise com fim e a análise sem fim" (tradução bem elegante, não obstante). Se, com talvez ousadia demais - o leitor será o juiz disto -, escolhemos citá-la diferentemente no corpo de nosso artigo, é porque a tradução atual do título nos parece servir muito bem à lógica binária. Ora, não se trata de opor um tipo de análise bem-sucedida, terminada, como o seria um produto acabado, a um outro tipo de análise, inacabada e por isso fracassada. O texto freudiano leva a conjuntura para um horizonte em que não reina tanto assim a preocupação de opor dois tipos de análise. Freud, em seu enunciado, designa apenas uma vez a análise cuja temporalidade é ao mesmo tempo finita e infinita. Esta aparência de contradição, que parece ser somente uma falha de coerência lógica em relação às nossas exigências lineares de temporalidades e causalidade, não deve ser esquecida ou retificada por uma preocupação de compreensão imediata. Esquematicamente pode-se compreender que o tempo requerido para fazer uma análise e terminá-la (resolvê-la) não é sua duração linear, mas o tempo da experiência do encontro com o sujeito do inconsciente. Momento em que se forma esta sobreposição do infinito e do contingente, momento de constituição da singularidade, a influência da infinitude sobre a sexualidade, que não pode ser senão inconsciente para o indivíduo. A análise terminada, estamos face a este sujeito do inconsciente que nunca deixamos de ser e que a ele voltamos. Wo es war soll ich werden. 


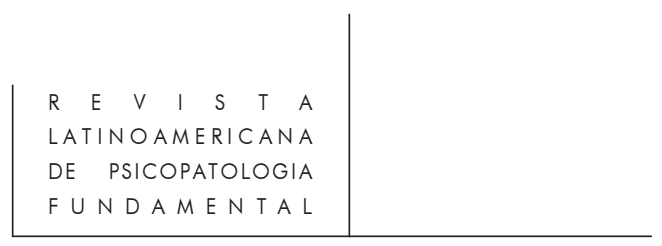

- a da neurologia, iniciando na época dos primeiros escritos analíticos freudianos, estendida a todos os campos da atividade humana (Brücke, Meynert, Exner);

- a dos primeiros modelos neurológicos que eram usados para pensar a psicopatologia (Charcot, Bernheim, Janet, Breuer);

- finalmente, a da filosofia clássica rica em especulações e modelos sobre os laços entre sujeito e pensamento.

Não convém, nem basta dizer que o objeto freudiano é o inconsciente. Vários autores, e não os menos importantes, asseguram, com razão, fazer um bom uso do termo inconsciente ${ }^{2}$. Conseqüentemente, não basta falar de inconsciente para se dizer freudiano. Em segundo lugar, uma interdisciplinaridade que não seja uma insipidez dos conceitos de várias disciplinas em uma mesma pseudolíngua deve se referir à teoria do sujeito e do aparelho psíquico. Estas noções estariam ou não presentes quando nos referimos à noção de inconsciente?

2. Dwelshauvers, em 1916, distinguia os seguintes tipos de inconsciente:

a) $O$ inconsciente psicopatológico, compreendendo tudo o que entra na composição das percepções sensíveis sem ser considerado pela consciência que percebe. Neste caso, o inconsciente pode ser caracterizado como "não distinto", "não determinado". Um inconsciente do mesmo tipo será igualmente aceito pelo psicólogo suíço J. Piaget.

b) O inconsciente automático, o automatismo psicológico de Pierre Janet, o "subconsciente". Trata-se de atos psíquicos que escapam à pessoa que os realiza no momento em que os realiza. Esta concepção do inconsciente é logicamente suposta pelas teorias em que a personalidade consciente, "secundária" ou "superior" se constitui liberando gestos habituais, automáticos. O "subconsciente", por mais "automático" que seja, seria quase sempre, para os que defendem esta concepção, uma forma "elementar", "primária" de consciência.

c) O coconsciente (Morton Prince, Assagioli), a dupla personalidade (Dessoir). Tratar-se-ia de atos psíquicos que se afastariam do eu normal e se sistematizariam de modo a constituir uma "segunda personalidade".

d) O inconsciente latente ativo: tratar-se-ia de idéias, de lembranças, de impulsos que aparecem brutalmente na consciência sem que se possa explicar de onde vieram, e dos quais dependeria a criação artística.

e) O inconsciente na memória: 1) Qualquer fenômeno de memória suporia a existência de representações existentes, mas não percebidas. O inconsciente seria, portanto, aqui, considerado como equivalente do não percebido. 2) Nas tendências, não determináveis como tais pelo sujeito. 3) Nas associações de idéias: surgem idéias na consciência cujo ponto de conexão original é desconhecido.

f) $O$ inconsciente afetivo. Trata-se daquilo que prepara nossos estados afetivos, que os torna duráveis, os fixa em sentimentos ou paixões, e escapa em sua maior parte à nossa consciência. Dwelshauvers propôs nomeá-lo inconsciente irracional ou passional.

g) $O$ inconsciente hereditário de Gustave le Bon, série de tendências hereditárias que se manifestariam nas crenças, atos etc. de uma dada população.

h) $O$ inconsciente racional (Dwelshauvers), forma de atividade mental desconhecida que estabeleceria ordem em nossa vida psíquica, principalmente instituindo progressivamente um tipo de síntese em nossas idéias. 
Além disso, o termo inconsciente é, em virtude de sua particularidade, com freqüência recebido em uma acepção pesada de contra-senso, por ser herdeiro direto demais da filosofia e dos ideais das Luzes. Este ideal cômodo leva a crer na faculdade de controle do real a partir do momento em que tivermos atravessados sua estrutura, sem que isto, em contrapartida, venha produzir modificações das categorias de nossas racionalidades.

Nestas circunstâncias, vê-se que é o estatuto da consciência que devemos novamente examinar. A consciência de um diverso sensível supõe uma antecipação de sentido. Com a consciência, um sentido que já estava lá encontrase reconstituído na fenomenalidade do ato de tornar consciente para si mesmo a existência desta ou daquela constelação significativa do sensível. O essencial se dá no plano de um jogo temporal que remete à presença do sujeito ao mundo, encontrando sua condição no percepto, no corporal e no linguageiro. O préconsciente é esta antecipação de sentido.

Freud encontra o problema da causação do mental no próprio interior de sua concepção da junção: aparelho psíquico/inconsciente. Tal base lhe dará a chance de forjar o conceito de inconsciente através de um raciocínio apto a reduzir a estranheza e a dissimilitude dos elementos que compõem uma classe de observáveis. Esta classe é construída por meio de uma demonstração que faz com que se juntem os lapsos, os atos falhos, os Witz (chistes), os sintomas e os sonhos.

Todos estes estados de emergência sintomática do pensamento dependem dos mesmos processos e demonstram a existência de um regime do pensamento que é irredutível ao pensamento consciente. Trata-se de fazer valer a noção de conflito no exame dos distúrbios do pensamento.

A atividade de pensamento provém da espera e produz temporalidade. Em relação a isto, o adiamento pelo pensamento é uma noção fundamental, já que introduz na capacidade de pensar a possibilidade de uma modalidade de desdobramento do tempo em relação e em reação à urgência do agir, à sua sujeição. Freud define esta função do pensar no adiamento do agir. Submetido a esta necessidade, o pensamento opera por tateamentos. Paralelamente, e no plano da técnica psicanalítica, examinemos os maquinários metapsicológicos de Freud.

Entre um perigo interno - o psiquismo que, como um órgão, desapareceria no abismo de sua atonia - e um enigma externo, uma falta na alteridade, a constituição do aparelho de pensar se baliza, primeiramente, por referências associacionistas. Após o estudo sobre as afasias, o Esboço se tornará o manifesto maior dessa época. A questão colocada por esse texto é a seguinte: o que é o psiquismo de um ponto de vista energético?

A este respeito, retomemos rapidamente o que Freud nomeava complexo de outrem no Esboço. Aqui, Freud introduz o princípio de identidade. Todos os mecanismos psíquicos terão como objetivo uma identidade entre a memória e o 


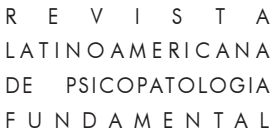

percepto, quando o sujeito vive uma tensão que não poderia se exaurir pela descarga motora e pulsional. Os processos mentais não são unicamente reservados para a realização de uma descarga motora ou biológica adequada. No ato mental o eu procura a identidade (princípio de identidade, expressão fundadora de uma filosofia da presença). A atração da imagem investida pelo desejo, por um lado, e a vigilância e a atenção, por outro, facilitam o processo de identificação da imagem mnemônica com aquela investida pela percepção. Temos aí uma préforma da atividade de julgamento. A energia psíquica não mais segue os trilhamentos primários; esta derivação implica, pelo contrário, um investimento dirigido do eu. Em certos casos a obtenção da identidade supõe um ato motor daquele que percebe. Há casos de reconhecimento em que a percepção não está absolutamente de acordo com os traços mnésicos cuja revivescência é desejada. Esta percepção é investida e permite ou associações sem atividade de julgamento, devaneios, ou o desdobramento da atividade de julgamento. Pode existir uma ordem ao nível do todo e distinções ao nível das partes. Reminiscência e conhecimento se encontram totalmente implicadas e possivelmente antagonizadas no momento da constituição da primeira subjetividade, quando a percepção de outrem se constrói em relação aos diferentes fragmentos de imagens que o sujeito tem de si mesmo. Freud parte do encontro entre a criança e uma pessoa, uma alteridade notável ao ser da mesma ordem que aquela que lhe permitiu e deu as primeiras experiências de satisfação e, portanto, também, seu primeiro desprazer (não vamos procurar em Freud ou Winnicott profundos soluços pela boa mãe generosa dos primórdios). Há, então, um interesse psíquico por este outro que é também o outro da potência: potência de dar e privar, de estar ou não aí, de responder à demanda ou recusá-la.

Vai haver aí um momento em que esta temporalidade da subjetivação, os diversos segmentos do reconhecimento eu-outrem vão se harmonizar. A cena do Nebenmensch não termina em perfeição. Ver-se no outro desemboca na unificação imaginária, mas sob a ameaça também de ser alienado do outro, caído dele. Reconhecemos aí uma impossibilidade, situada além de uma impotência: o encontro e o confronto com a alteridade nos torna transparente sua vontade a nosso respeito. Sem simetria. Sem exaustão possível de toda a história de um sujeito, nem mesmo de leitura possível do conjunto dos textos esparsos e palavras vagabundas demais e coaguladas demais que o engastam e o atravessam. Ora, a este buraco analógico com a história corresponde o corpo esburacado, não linguageiro, não reclamado pela castração. E é no momento da articulação freudiana do mito primitivo deste complexo de outrem, que se desvela também que é sobre um apagamento inaugural, um esquecimento, que se constrói a primeira certeza relativa ao que reúne o sujeito ao Outro. O princípio de prazer se encontra, então, incumbido de uma carga exorbitante, busca da identidade 
com o primeiro percebido, com o primeiro a ter feito traço, enquanto o próprio princípio do traço implica uma perda irremediável, um afastamento entre percepção e memória. Mais adiante em Uma nota sobre o bloco mágico, Freud descreve a exclusão mútua entre o sistema percepção/consciência e a memória: "o inexplicável fenômeno do consciente aparece no sistema perceptivo, no lugar dos traços duráveis." 3

Freud começa descrevendo como a experiência da satisfação dá lugar a um trilhamento e como a rememoração imagética da pessoa compassiva e da situação de apaziguamento se encontra reinvestida com a ressurgência da necessidade. Para isto, este investimento do traço mnêmico não poderia ser explicado por um trilhamento puramente mecânico, já que o objeto depende, em sua constituição, do registro do outro humano. $\mathrm{O}$ apelo e o grito se esvaziam sobre o fundo da ausência de objeto. A representação de palavra substitui-se ao objeto e se torna independente; o grito é pensável como o umbigo da metáfora. Já na Carta 52, colocava-se que para ter acesso à representação de palavras, o psiquismo deve passar pelo princípio de diferentes estratos de registro e traduções ou diferentes substituições que implicam perdas irremediáveis. O grito é este momento em que, se o Outro responde, a criança desconecta a coisa de seu grito, "eleva o signo à função de significante", propõe J. Lacan. ${ }^{4}$

Com a ressurgência da necessidade ou da tensão que lhe é própria, a imagem memorizada da pessoa compassiva se encontra investida. Este investimento fornece, antes de tudo, algo análogo a uma percepção, ou seja, uma alucinação. "Uma aspiração ardente cria no eu uma determinada tensão e, em seguida, um investimento da representação do objeto amado... A descarga deve ser adiada até o momento em que as informações relativas à qualidade provem que o investimento é mesmo de ordem perceptiva. Quando uma percepção idêntica ou semelhante à idéia de desejo se produz, ela encontra seus neurônios pré-investidos pelo desejo. A diferença entre a idéia e a percepção desencadeia o processo mental que se realiza quando os investimentos perceptivos excedentes conseguiram descobrir a via em que se confundem com os investimentos ideativos. Chegamos, então, a uma identidade."

Desta passagem do Esboço, depreende-se que o investimento do objeto não pode ser considerado em uma operação puramente mecânica, desprezando um sujeito. A identidade é justamente um acontecimento a ser obtido, que vem perturbar o processo da descarga, impondo um desvio de investimento. Pois em sua própria constituição o objeto depende do apelo, ou seja, do grito. $\mathrm{O}$ resultado disto é uma perda do outro entre seus traços e seu ser (Das Ding). O que se

3. P. 120.

4. "Subversion du sujet et dialectique du désir", in Écrits, p. 891. 


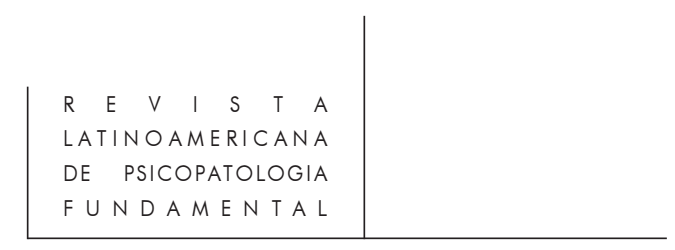

revela no distúrbio do pensamento é o distúrbio do complexo de outrem, o objeto não dependendo de uma percepção real. Esta é a fissura que permite à identidade cindir-se e lhe ordena que se reconstrua.

A partir do Esboço, a linguagem do pensamento para Freud é construída por associações verbais que ligam, primeiramente, o sistema dos neurônios impermeáveis aos neurônios que servem à representação de palavras. A associação verbal servirá, antes de tudo, de descarga e regulação, e, secundariamente, como meio de comunicação. "A meta, o fim de todos os processos meditativos é a instauração de um estado de identidade", o que supõe uma renúncia à via da descarga. A associação da imagem sonora e da imagem de percepção é tal que, produzindo ou reproduzindo a satisfação, conferirá suas qualidades ao objeto. Em função do princípio de prazer se efetuará a seleção. Em oposição à prova de realidade está a descoberta do objeto em sua ausência na realidade.

Em Esboço, a fonte maior da qualidade de excitação psíquica vem do exterior, enquanto nas conceitualizações posteriores virá do corpo. Mais precisamente das pulsões, desta zona fronteiriça entre o somático e o psíquico. A pulsão não tem correspondente direto no psiquismo. Confrontado com tal hiato, Freud postula o nascimento de uma associação que faz uma "solda" entre a pulsão e um elemento do aparelho psíquico. Tal conexão, fortemente ligada, irá funcionar como um representante da pulsão. Este representante não se parece com, ele reúne. Por estar destinado a articular-se a outros representantes, ele concorre para forjar uma representação. Do mesmo modo, há no psiquismo traços psíquicos não-ligados que guardam seu caráter de traços em virtude da ausência de ligação entre eles. Mas o fato de um destes traços se encontrar ligado a um outro faz com que percam, então, todos os dois, seu caráter de traços para fazer parte integrante da tela de uma lembrança, que é sempre uma representação.

Mas nos resta a questão de saber em que base do ser vivente e do psíquico tais agenciamentos encontram seu ponto de apoio. Antes disto, estamos no registro dos significantes primários, pré-lingüísticos. Representações de percepções (que Freud chamará de Percepções-signo), que não são agenciadas e reunidas senão por extensões de funcionamento do corpo, comandando as articulações. Tratase de uma modelização da associação que leva em consideração a construção psíquica do corpo. Aqui encontra-se presente a menção de excitações, manifestações fisiológicas que acompanham o processo de pensamento. Nestes feixes de Percepções-signo, condensam-se duas operações psíquicas: os princípios da tradução e as lógicas da identificação.

Com relação a isto, o que indica a teoria do sonho, e particularmente a noção de "consideração da figurabilidade", é que o aparelho da alma não tem outra saída para fundar, depois gerar a permanência dos traços do infantil, senão espacializando o tempo, figurando-o pelo espaço. É uma combinatória. 
Como o ser falante pode receber alguma apreensão destes processos de pensamento? Unicamente à medida que se produzem falas, e isto por duas razões. Por um lado, os indicadores verbais se tornam indicadores da realidade do pensamento; por outro, os objetos maiores do mundo humano são objetos falantes.

Uma invenção que retornará, muito mais tarde, com Uma nota sobre o bloco mágico, faz se desdobrar uma problemática do trilhamento que se conforma, cada vez mais, com uma metáfora do traço escrito. Para Freud, o paradigma do aparelho psíquico remete a uma modelização da inscrição, na passagem do traço para a letra. O modelo da escrita se substitui ao modelo do registro para explicar este paradoxo, no qual é necessário demonstrar, ao mesmo tempo, que no psiquismo há permanência do traço e virgindade da substância de recepção.

Tomemos, agora, a Traumdeutung (1899, publicada em 1900). Na realidade, se se tratasse apenas de ter uma base para compreender os atos mentais em uma visão de psicologia genética, então, a atividade alucinatória deveria, pela virtude do desenvolvimento das estruturas mentais do conhecimento, desfazer-se no nicho dos únicos momentos de onirismo. O Real se ofereceria, assim, dia após dia, aos homens de boa vontade e de bom caráter para ser dominado. No texto freudiano - e isto constitui o manifesto que é $O$ mal-estar na civilização (1930) - não é nada disto. Contrariamente a qualquer idealismo, Freud formulou o princípio de prazer como nunca antes havia sido formulado o prazer, operando uma dupla refenda - hedonismo e ética. Pois antes de Freud, o prazer servia sempre para definir o Bem; era em si mesmo satisfação. Freud toca, na interrogação sobre o prazer, a ponta da Verdade do sujeito e do sujeito sexuado. Com ele, o eixo sofrimento-prazer não mais pode ser a simples tradução, ao nível do mental, da circulação da quantidade de energia psíquica, já que intervém o meio da linguagem e da cultura, ou seja, da significação simbólica e ética do ato e do ato de pensar em um universo cultural, simbólico.

À medida que avançamos na descoberta de Formulações sobre os dois princípios do funcionamento psíquico, encontramos, no que tange à significação e à função do pensamento, uma reviravolta de ponto de vista, que é capital. O pensamento, até então apresentado como uma consequiência da intercessão do princípio de realidade, constitui o campo em que a libido vem se satisfazer em construções fantasmáticas. O trabalho do recalcamento atinge, justamente, esta atividade fantasmática com a consequiência que disto se deduz. Estes fantasmas, que são as fontes específicas do prazer, permanecerão ainda mais inatingíveis pelo princípio de realidade, pois ao serem atingidos pelo recalcamento, escapam, assim, à esfera do conhecimento. O campo regulado pelo princípio de prazer não mais está, por este motivo, limitado à única via regressiva da atividade alucinatória. Prazer, fantasma e pensamento mudam de sentido. O pensamento 


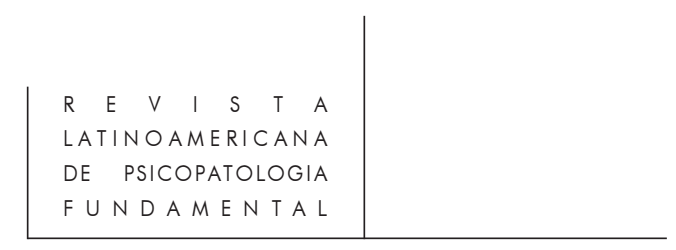

constitui um desvio que o sujeito empreende para obter indiretamente o que the é recusado. O trabalho do pensamento é conduzido pela busca da Befreidigung (termo que significa literalmente apaziguamento, traduzido em uma aproximação excessiva pelo termo satisfação).

A particularidade deste modelo é colocar a tese de uma verdadeira atração da libido pelo inconsciente. De formação patogênica, este último torna-se um conceito fundamental, um fato de estrutura universal que implica modos de subjetivação singulares. O corolário desta introdução da subjetividade é que o campo submetido ao princípio de prazer é aquele das representações, as quais fornecem ao sujeito suas bases identificatórias. A teorização de modelos do pensamento unificará, a partir desta modificação tópica, as noções de pensamento e recalcamento. Compreender-se-á, então, que nenhuma teoria do psiquismo, preocupada em se referir a uma teoria psicanalítica do inconsciente, pode recusar considerar a capacidade de ficção inerente à atividade de pensar. Todas as possibilidades de novidade de que o aparelho psíquico dispõe são dependentes não dos estoques de representações e dos traços, mas do modo com que a economia libidinal investe e usa este estoque, deformando-o e dele se apropriando. Mas a partir disto como uma relação com a realidade é possível? A partir do momento em que o princípio do erro é colocado no sujeito, a partir do momento em que o sujeito é submetido a esta tendência primeira para a alucinação, o eu é capaz de deslocamento ou mesmo defasagem temporal na atividade de pensamento de seus julgamentos de existência.

Freud, inicialmente, havia concebido uma "máquina", um aparelho no qual os processos secundários deviam remediar o erro. Ora, a clínica das psiconeuroses indica que o erro de julgamento remete a um fato de estrutura. O erro não é anomalia. O julgamento divide o sujeito não entre verdade e erro, mas entre ser e pensamento, que traduz a tensão do inconsciente e do isso, mas atravessando-os com a linguagem. Trata-se de um conflito de instâncias, mas isto vai se tornar o reforço de uma impotência por um impossível, em virtude da linguagem. A psicanálise vai, então, encontrar uma nova fundação de sua teoria da linguagem quando os conflitos em jogo na psique encontrarem um plano diferente daquele da polêmica sintomática entre desejo e interdito em virtude da introdução da hipótese da pulsão de morte.

Em 1920, Freud estabelece a segunda tópica, que leva a uma outra concepção do aparelho da alma (ou aparelho psíquico). Esta concepção implica duas modificações radicais:

- Primeiramente, a economia psíquica se revela regulada não mais pela tendência ao retorno ao estado do nível mais baixo da tensão, mas pelo automatismo de repetição. Em termos clínicos, nada é menos inoportuno do que lembrar isto: não é mais possível "contar" com a boa vontade de uma pessoa para curar- 
se, proveniente de uma parte sã, aliada, guia e consoladora do terapeuta, já que o sujeito deseja se lançar em uma experiência, não aquela da tranqüilidade da alma, mas uma experiência encurralada nos veios da repetição. Esta experiência, cujas premissas são desejadas, depende da preocupação persistente de reproduzir o mesmo tipo de tensão, aquele a que a economia libidinal está acostumada desde os acontecimentos significantes da infância.

- Em seguida, o recalcamento, de mecanismo de defesa contingente - ele se apresentava inicialmente como um acidente -, fica articulado em torno de um recalcamento estrutural primeiro: aquele que o sujeito encontra quando ele advém ao mundo ou irradia a linguagem. O recalcamento não mais está ligado à desgraça do sujeito ou à sua pusilanimidade. Ele é constitutivo do funcionamento psíquico. Enfim, outros mecanismos diferentes do recalcamento são teorizados nas tentativas freudianas para explicar a origem e a direção destes pensamentos que são os julgamentos de realidade.

Não há julgamento no inconsciente, o julgamento só vem à luz ao nível da censura. Tal radicalização da questão do julgamento seria, ao que parece, o que também permite, a Freud, não se deixar invadir pela tirania da psicologia e continuar fazer ferver o caldeirão de sua feiticeira metapsicológica. Para uma teoria do conhecimento, o julgamento, a condenação de existência supõem sempre um objeto qualquer. Em Freud, a separação em relação às correntes dos psicólogos de seu tempo (Jerusalem, Mach) desemboca em um outro estatuto do sujeito diferente daquele que se define pela soma das operações de pensamento sobre uma conciliação do ser e do pensamento. $\mathrm{O}$ desenlace da análise também deveria ser compreendido como o fato, em que além, bem além das assimilações sintomatológicas pela exaustão e elucidação do recalcado, o sujeito chega a uma certeza última: a angústia é o momento de modificação das identificações, mas também o instante de estupor ou de terror, onde se revela que não há garantia da garantia, em que não há Outro do Outro, diz-se hoje em dia, quando acontece o encontro com o próprio vazio da coisa.

O julgamento a respeito da realidade é frágil. Sua inconsistência é o ponto estruturalmente necessário ao desenlace de um tratamento. A denegação, mecanismo de defesa específico da neurose obsessiva, também é a possibilidade de um julgamento negativo originário. ${ }^{5}$ Se ela está referida ao mecanismo de

5. A argumentação de Brentano, bastante gnoseológica, exercerá uma profunda influência sobre a teoria do pensamento em Freud e igualmente para toda a filosofia da linguagem. Advinda de uma fidelidade pouco comum a Aristóteles, a definição ontológica da verdade dará lugar a uma concepção totalmente oposta. Há somente atos de julgamento e a verdade deve se fundar sobre a evidência destes atos. Qualquer julgamento positivo é um julgamento particular; os julgamentos universais devem ser entendidos como julgamentos negativos. O conhecimento ético é fundado 


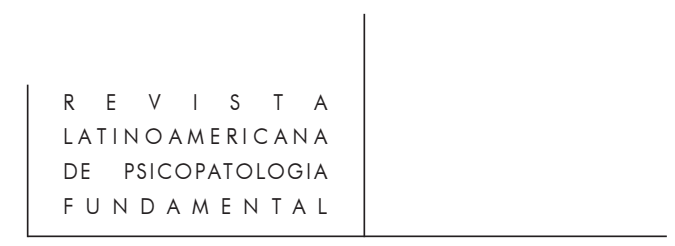

pensamento, a negação ${ }^{6}$, este último mecanismo, permite admitir em uma simbolização possível o retorno do que foi expulso. Entre este julgamento produzido pela tarja da censura, encontrando seu hábito retórico na denegação, e esta ausência fundamental de julgamento, primitivo Austössung, o pensamento da realidade deve, sem dúvida, ser sustentado, porque decepciona o desejo.

Todavia, o problema do sujeito permanece onipresente na obra de Freud eu ou sujeito? A instância do eu é, ao mesmo tempo, centro organizador (e é o Ich do Esboço) e superfície de projeção de superfície (e encontramos aí o Ich de Mässen Psychologie und Analyse das Ich - 1921 - do Es und das Ich - 1924). Com $O$ eи e o isso, Freud conseguiu desfazer a ilusão de uma autonomia subjetiva, ou seja, uma identidade entre a essência do indivíduo e seu eu. Tem-se, além disso, uma relação de tensão entre o eu e o ideal. A resistência ao descentramento que o inconsciente freudiano produz no sujeito foi intensa e muito dogmática. Pode-se explicar assim o recurso episódico, mas recorrente, ao velho conceito de "personalidade", ao longo da história da psicanálise, noção que, longe de ser a peça faltante para as teorias metapsicológicas de Freud, é, na realidade, estranha à psicanálise. De origem psicológica, hoje prolongada por certos usos do conceito de Self, ela traz de volta as promessas psicológicas de uma hipostasia da reflexividade, de um sujeito do qual se supõe conhecer o inconsciente para dele ser o mestre.

É verdade que o texto freudiano opera de uma forma que se situa fora da problemática do sujeito da consciência, mas ele continua imerso na episteme clássica. No entanto, se a descoberta freudiana é justamente a do desejo inconsciente e de sua formalização, então, uma clínica psicanalítica se funda apenas no estudo da ligação entre a variável e o objeto do fantasma.

Freud vai dar à sua teoria do fantasma uma amplitude decisiva e um alcance lógico com o caso do homem dos lobos. Essa monografia é um texto articulatório que marca uma nova orientação de sua pesquisa e de seu modo de conceber a direção de um tratamento. Orientação não em direção a um sentido sexual a ser revelado, mas em direção a um real a ser reconstruído. Freud obstina-se em remontar aos extratos mais antigos de construção da memória; ele se atém a especificar as datas, mas, nesse trabalho, nada do procedimento de um detetive ou de um arqueólogo; na reconstrução não é a verdade material que é visada, mas a verdade como efeito, a causa como construção. Tentativa não de fazer ressurgir em sua nudez a realidade antecedente, mas tentativa de fundar o fantasma.

sobre duas emoções: amor e ódio; o dever se fundando sobre uma ética da intencionalidade. (cf. Kastil, 1951)

6. Die Verneinung, 1925. 
A verdade é visada... como efeito. É justamente o sexual que organiza a memória. Freud, a partir do caso do homem dos lobos, inclui em sua teoria do fantasma a problemática da castração. Ele não aposta mais nas chances de exumação de uma historicidade anterior ou primitivamente estabelecida. É também o tipo da realidade que se encontra aí especificada. A realidade freudiana inclui a ordem da castração. "O sucesso", escreve Freud, "foi atingido ao preço de um rasgo no eu, rasgo que nunca mais sarará, e que, com o tempo, crescerá."7 A consideração da realidade faz-se pagar pela perda de uma parte do isso. Em tal perspectiva, é enunciado que o trabalho no tratamento, sob seu duplo aspecto de "reconstrução" e de "decisão" - e não mais unicamente de interpretação -, inscreve um real no cerne de sua intenção: o real da castração. Ora, a castração não pode nem ser verificada com constância, nem de uma vez por todas. O sujeito não pára de a ela retornar no movimento próprio do estofo imaginário de suas posições subjetivas: entre desmentido e reconhecimento. A verdade inscreve seu trasvestimento em uma colocação em relato. Ficção no futuro do pretérito que não vale como monumento de sentido decisivamente instalado e causal, mas tem valor de um tempo em que ela oferece a ocasião de inscrever e de trabalhar uma verdade que a transcende.

De um lado, cada repetição se inscreve a serviço da ligação e do desconhecimento; de outro, cada repetição revela um resto que escapa à ligação e à interpretação. Uma parte da experiência "vivida e originária" escapa à ligação. É neste inassimilável que se pode situar o núcleo real do fantasma. A repetição se torna, ao mesmo tempo, produtora do objeto impossível e do corte do sujeito. Enfim, a compulsão à repetição não é, face ao sintoma, nem efeito homogêneo, nem suposto agente do recalcamento, mas sim sua própria causa. O sintoma, com a introdução da hipótese da pulsão de morte, não mais é a formação de compromisso, meio de traduzir e ressoldar um conflito; ele é investido de uma outra insistência resultante de um fato irredutível: a impotência da pulsão em encontrar o objeto adequado para satisfazê-la.

Ao descobrir a parte do que é rebelde à leitura simbólica, Freud destaca um aspecto do funcionamento psíquico que ultrapassa o automaton. E este real não pode receber um estatuto discursivo. O que Freud demonstra com seu exame da Verneinung é que os dizeres de um sujeito não se deixam reconduzir ao esquema de uma significação. O "não" do sujeito não se opõe ao "sim", no sentido em que tanto um quanto o outro conotariam a verdade ou a falsidade de uma proposição. O "sim" é, com freqüência, tão equívoco - senão mais - do que o "não", e não equivale, a cada momento, a uma confirmação. Aí ainda, a modalidade da transferência entra em jogo de modo bastante decisivo e produz

7. "Le clivage du moi dans le processus de défense", p. 284. 


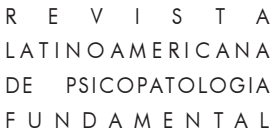

a temporalidade não sugestiva de um tratamento, temporalidade por onde se separam interpretação e construção. A construção do analista não é um fim em si, ela é apenas suposição, é a parte destinada ao paciente que dá força decisional à construção. Freud insiste, então, sobre o que pode se articular pela via de uma enunciação; a verdade como efeito é mais importante do que uma correspondência com a realidade oculta. Não se trata mais de reencontrar um elo esquecido, mas de remediar uma lacuna; a "verdade histórica" somente se sustenta ao ser construída.

A metapsicologia freudiana implica, então, que todo julgamento de existência se formule apenas com uma única decisão: por um "não é isso". Assim, o que eu vejo não corresponde àquilo de que me lembro e que é o verdadeiro objeto de meu desejo. Em torno de um vazio inicial, que diríamos ser aquele que cria o recalcamento originário, qualquer julgamento de existência se funda sobre uma repetição perpétua de um "não é isso", como conseqüência da estrutura metonímica da fala do sujeito desejante. Negação pela qual se afirma o sujeito, em um lugar que estará vazio de significantes. Por não assumir o sujeito em tal lugar, o mundo se cliva. A Bejahung freudiana supõe uma ruptura com o tratamento analógico que procede a uma adequação verificada entre percepção e lembrança. A afirmação da existência deriva, pois, de uma utilização precisa da negação. Em contrapartida, quando "há retirada dos componentes libidinais", diz Freud, é o negativismo que assume o lugar desta negação fundadora.

A este ponto de nosso desenvolvimento, é preciso ainda acrescentar que o ponto de vista freudiano não está desconectado do antropológico. Freud relacionou com muita precisão o funcionamento de uma denegação neurótica com a função paterna, inscrevendo, desde Totem e tabu, a passagem à dominação pelo princípio de realidade no rol desta função. Não esqueçamos que a realidade, em Freud, por incluir a realidade da castração, está subordinada à função paterna. É por isso que a matriz da Verneinung, "o modo original de elisão significante" não pode estar separada da lógica da função paterna.

Houve um tempo - ou melhor - os tempos de Freud. Houve sua relação firme com a racionalidade, sua igual desconfiança em relação à medicina e à religião. Sua metapsicologia, a quem ele confiou a carga de tornar figurável em fantasma a relação com a arqueologia da violência na fala. O sujeito que daí era deduzido não podia se alinhar completamente sob as hospitalidades do eu, por trás das bandeiras do indivíduo. Inquietante estranheza, clivagem, sobras dos lutos, o sujeito freudiano, onipresente não era, às vezes, do mais que o resultado de um cordão de divisão, cuja castração dava o princípio lógico e o recurso final. A psicanálise tem isto de inexorável: o originário se dá aí cada vez mais esburacado, alterado. Os tópicos fronteiriços estão cada vez mais subvertidos à medida que os ideais do eu são atacados ou aceitos pelo que são - os sintomas 
são modos de gozo do inconsciente que a ficção recobre. A episteme das ciências "avança" também desconstruindo o sujeito transcendental que, de Descartes a Kant, tinha organizado o início e o apogeu da ciência e da lógica clássica.

Mas a abordagem contemporânea da questão do sujeito, nas ciências fundamentais, por mais transcendental que seja, é também concebida sem invocar um sujeito transcendental - o que não significa que não haja sujeito no processo de aquisição dos conhecimentos. Mas isto quer dizer, em contrapartida, que não é mais pensável colocar na base da possibilidade de tudo representar e de tudo pensar a unidade de um sujeito ou de uma consciência que seria em si mesma idêntica no conjunto de seus atos de enunciação e/ou entendimento. É esta nova teoria pós-newtoniana do sujeito que requer, por exemplo, o problema epistemológico das interpretações divergentes da mecânica quântica. A epistemologia que atua como uma promessa da ruptura do paralelismo entre julgamento e categorias (estes dois pilares da "unidade originária da apercepção transcendental") ultrapassa o pensamento da relação de um sujeito com um objeto. Mas é aqui a abordagem fenomenológica que dá sua consistência a esta nova epistemologia ${ }^{8}$. Mostra-se, na análise fenomenológica do fato enunciativo em física, que o que sustenta o enunciado é uma topologia nova que resumiria bem a sobrevinda de uma relação de exterioridade não-completa. A superação da relação sujeito/objeto que se opera em psicanálise implica que o sujeito do desejo seja justamente aquele que, por ser dividido pelo significante revela um buraco, uma aporia. A lógica da teoria analítica se preocupa com os trabalhos dos lógicos da incompletude, ela é ciência das suturas não fechadas, dos correlatos não totalmente ligados.

Daí uma conclusão. Se é, por um lado, a refenda do sujeito pelo significante, e se, por outro, é a tomada lógica e sua fixação por um lugar tomada pelo vazio erógeno do objeto, que fazem com que o sujeito sobre o qual trabalhamos seja exatamente aquele, a-psicológico, que consagra a episteme das ciências modernas, o esclarecimento deste sujeito, enquanto efeito e variável, necessita a recondução de uma experiência singular. E por isso mesmo, o modo de produção da verdade que caracteriza a situação psicanalítica é distinto da verificação. Ele se autonomiza aos olhos das exigências da produção de verdade científica. Neste sentido, não pode haver aí uma ciência das singularidades, singularidades cuja prática é a psicanálise.

É particularmente redutor pensar a psicanálise apenas como uma episteme operante sobre o sujeito da ciência para dela receber os princípios de construção do matema. Sua tarefa é especificar o mais correto dos modos de emergência do real, os modos em direção aos quais o desejo gravita sob o risco de aí se

8. P. Bergé, 1991. 


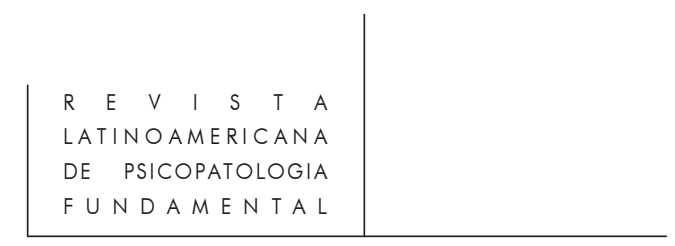

purificar, ou seja, de privar-se de todo o erotismo. Pois é ao manter velado este ponto de real que o fantasma se faz passageiro do eros.

"Assim como a experiência somática não fabrica o fato psíquico, assim como as exigências sociais não provocam o recalcamento, assim como os acidentes de infância não fazem a história do sujeito, assim como as particularidades lingüísticas, os idioletos e as criptonimias não constituem a verdade do sujeito; da mesma maneira, o 'atual' não faz a memória ou, ainda, os restos diurnos não criam os sonhos. Estes elementos permitem, acima de tudo, entender e inscrever uma história que, sem eles, permaneceria em sofrimento. Assim fazendo, ao inscrevê-la, eles, em contrapartida, se tornam parte, substância significante, inseparáveis, indissociáveis", escreve R. Gori ${ }^{9}$. O sujeito se encontra, então, no determinismo inconsciente, constituído por sua história e, principalmente, pelas zonas de complacência do somático e do órgão com a fantasmática, do significante e do acidente, zonas de complacências que definem redes e pontos de a posteriori em que o trabalho da língua afirma seu poder de fabricar a perda e o retorno, de criar a tradução em que se vela a inércia camuflada dos traços que o objeto deixa em seu desaparecimento. Mas também a causação do sujeito por aquilo que neste a posteriori fixa a "substância" e o "significante". No espaço da situação de tratamento estas zonas se deslocam na e pela transferência. Também o pensamento psicanalítico da submissão do sujeito à sua causação pelo significante pode, rapidamente, desembocar sobre uma concepção incorporal do sujeito. Ele se esquece, justamente, de que a atonia subjetiva do sintoma provém de uma fixação do erógeno depositado nas palavras petrificadas e nas hermenêuticas precoces que todo indivíduo constrói, enquanto cada sofrimento psíquico reclama pela construção do sintoma um aumento de significação - quando ela não leva o indivíduo a romper a bolha que contém sua imagem narcísica (experiência de dissolução da psique própria a certas formas de adição ou a determinadas errâncias).

Uma dedução se impõe então. Se o narcisismo e suas falhas são o que causa o mental, é justamente pela finalidade de operar com o real que, pela psicanálise, se causa o sujeito. A referência cartesiana, tão importante em Lacan no que se refere à topologia, não pode se perder mais adiante. $\mathrm{O}$ sujeito que produz a psicanálise é, por um lado, análogo ao sujeito da ciência - referido à incompletude e produzido por um sistema de escrita -, mas não é menos irredutivelmente causado por aquilo que justamente a ciência não poderia considerar: o sujeito desejante. Da mesma forma, ainda que a epistemologia das ciências condene tanto o sujeito cartesiano quanto o sujeito transcendental, a psicanálise e a ciência não estão destinadas a se unificarem.

9. Roland Gori. A prova pela fala. São Paulo, Escuta, 1998, p. 180, grifo nosso. 
Se a descoberta de Freud é justamente a do desejo inconsciente, de suas lógicas e de sua eternamente incompleta exaustão simbólica, aparece então o sentido que há em voltar à noção de "causalidade" em psicanálise: trata-se de articular o pensamento do trabalho de fala na análise com uma epistemologia possível da psicanálise, isto no momento em que o trajeto freudiano, sua racionalidade centrada em torno do destino da inscrição do traço, está copiosamente ameaçado, com bastante freqüência considerado como um arcaísmo no seio do qual as ciências bitoladas devem fazer uma pequena faxina.

A metapsicologia freudiana continua a nos importar hoje em dia, não como descrição de um psiquismo, mas como ficção, como construção de um epos que guarda o traço de uma violência e de um apagamento originário, e que desenha os seus movimentos de transferência. Somos os contemporâneos da concepção freudiana da linguagem que dela faz o lugar certo para inscrever, levar e novamente dar corpo plausível para as diferentes variações dos trilhamentos. A significação não se dá sem os efeitos do deslocamento; a fala não se dá sem reorientar o corpo erógeno. Corpo fragmentado, com suas marcas de quebras e seus estilhaços, é, ao mesmo tempo, a colocação de uma relação singular com a lalangue, de um cruzamento que vem colocar semblante na lalangue, um corpo e uma história deste corpo que se apresentam: um corpo que reencontraria uma inscrição e, mais ainda, uma vetorialização nova em um espaço e em um tempo.

Especifica-se, então, uma definição da causalidade psíquica que integra o Édipo, mas que, ligada ao narcisismo e à morte, o supera. Assim fazendo, o tratamento acentua a densidade do ser, assim como o sujeito não é mais este intrometido incompreensível que a lei do significante deixa para sempre perdido, não é mais indefinidamente este objeto sacrificado ao outro.

De sua causalidade talvez tenha encontrado, a partir do real, o estilo de sua resposta.

\section{Resumos}

El proyecto de este artículo es trazar nuevamente un camino. Partindo del "engendramiento mutuo del aparato psíquico y del aparato de lenguage" (A. Green) para encontrar, en el examen de los modelos del pensamiento y del juício en Freud, los princípios propios de aquillo que, al causar loi psíquico, causa el sujeto y sus líneas de división. Enseguida, examina la problemática de la realidad del habla y del objeto en el tratamiento para contribuir con algunos granos en el debate: psicoanálisis y epistemología contemporánea.

Mostrando, aqui, que la causalidad que está puesta en la intimidad del sujeto no es un "punto de partida" dado para una progreamación irreductible del sentido vivido, tentaremos de indicar que la racionalidad psicoanalítica va más lejos de lo que queremos admitir. 


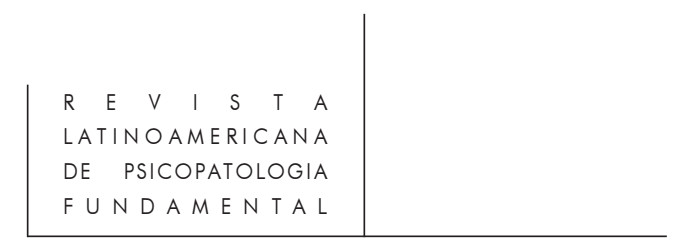

Cet article se propose de retracer un parcours. Partant de "l'engendrement mutuel de l'appareil psychique et de l'appareil de langage" (A. Green) pour rejoindre, au travers de l'examen des modèles de pensées et de jugement chez Freud, les principes mêmes de ce qui, en causant le psychique, cause le sujet et ses lignes de division. Ensuite, il se penche sur la problématique de la réalité du langage et de l'objet dans le traitement pour apporter de l'eau au moulin du débat entre psychanalyse et épistémologie contemporaine.

Montrant alors que la causalité impliquée dans l'intimité du sujet n'est pas "un point de départ" donné pour une programmation irréductible du sens vécu, il cherche à révéler que la rationalité psychanalytique va bien plus loin que nous n'aimerions l'admettre.

This paper is aimed at retracing an itinerary. Starting from the "mutual generation of the psychic and language apparatus" (A. Green) it reaches, through Freud's thought and judgement models, the very principles of what, causing the psyche, causes the subject and its splitting lines. From that point, it goes through some problems of the speech and object reality in the treatment as to provide the debate between psychoanalysis and contemporary epistemology with some ammunition.

106 Then, after showing that the causality involved in the intimacy of a subject is not a "starting point" given for an irreducible programming of the lived meaning, it tries to pinpoint that the psychoanalytic rationality goes far beyond what we are prone to admit. 